\title{
Orthodontic Treatment of Anterior Dental Open Bite with Drawbridge Effect: A Cose Report
}

\author{
Dr Basanta K Shrestha \\ Asso Prof, Orthodontic PG Section, Institute of Medicine \\ Tribhuvan University Teaching Hospital, Kathmandu, Nepal
}

Correspondence: drbkshrestha@gmail.com

\section{ABSTRACT}

A young lady presented to Department of Orthodontics with a chief complain of gap between upper and lower front teeth. On analysis she had Class I dental and skeletal malocclusion with proclined and forwardly placed incisors, and open bite. The treatment was carried out with extraction of all four first premolars and retraction was done with the help of mini-implant screws. Successful correction of open bite was achieved with "drawbridge effect".

\section{INTRODUCTION}

Open bite is a malocclusion characterized by lack of vertical overlap between the maxillary and mandibular dentition. Openbite may be anterior or posterior. Profit ${ }^{1}$ defined anterior open bite as 'no vertical overlap of incisors'. An anterior open bite (AOB) is a negative overbite between the incisal edges of the maxillary and mandibular anterior teeth, with the posterior teeth in occlusion. The prevalence of anterior open bite ranges from $1.5 \%$ to $11 \%$ and varies among ethnic groups, and by age and dentition. ${ }^{2-5}$ The various etiological factors thought to be responsible for causing open bite includes unfavorable growth pattern, heredity, digital habits, and tongue function. ${ }^{6}$ Some studies have found a correlation between oro-facial musculature and facial structures, suggesting a relationship between weak musculature and a long face anterior bite pattern. ${ }^{7.8}$

For the successful treatment of open bite, it is necessary to identify the contribution of skeletal component. As such Sassouni? classified open bite into dental and skeletal. Dental open bite is associated with some or all of the following clinical features:1,10-13 normal craniofacial pattern, proclined incisors, under-erupted anterior teeth, normal or slightly excessive molar height, mesial inclination of posterior dentition, failure of eruption of teeth without known etiology, divergent upper and lower occlusal planes, no gummy smile, no vertical maxillary excess, thumb and finger sucking habits, tongue thrusting habit, without remarkable cephalometric findings. Skeletal open bite is associated with one or more of the following features:1,10-14 steep mandibular plane angle, increased gonial angle, short mandibular ramus, downward rotation of the posterior part of the maxilla or palatal plane tipped up anteriorly, increased lower anterior facial height, decreased upper anterior facial height, increased anterior and decreased posterior facial heights, increased flexure of the cranial base (Na-S-Ba), steep anterior cranial base, shorter nasion-basion distance, small mandibular body and ramus and retrognathic mandible.

The treatment of anterior open bite is dependent on the etiology of malocclusion, age and the expectation of the patient. Mizrahi ${ }^{15}$ described four modalities of treatment: growth modulation; orthodontic mechanotherapy; orthognathic surgery and the combination of two or more of the above.

It is important to determine which form of treatment is the most suitable for each individual case. In case of dental anterior open bite in adult patients, extraction and retraction have been recommended to reduce overjet and open bite and elongate anterior teeth by a "drawbridge effect". 11, 16,17 A case report is presented here where the management of dental open bite is carried out by extraction and drawbridge effect. 

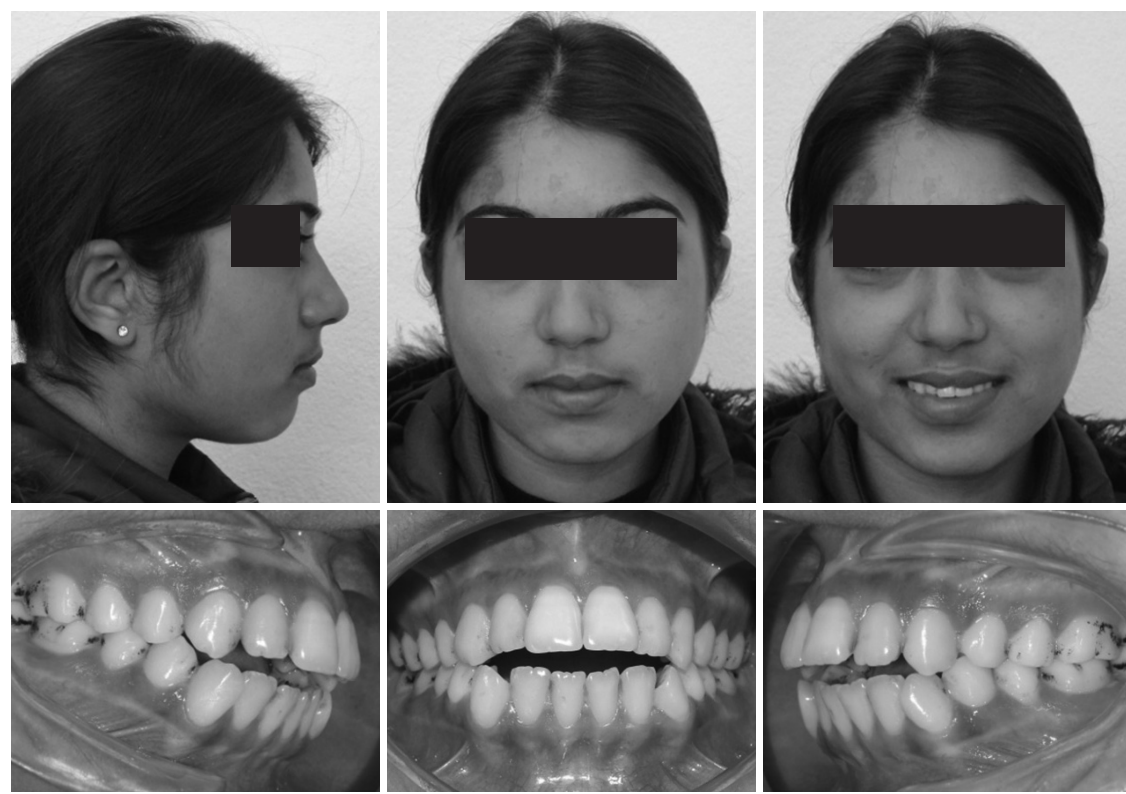

\section{CASE REPORT}

A young lady (DOB February 16, 1990) was presented to our department with the chief complain of gap between upper the lower front teeth (Figure 1).

On examination she had mesoprosopic face with convex profile. On intra-oral examination, she had Angle's Class I molar relationship with anterior open bite of $5 \mathrm{~mm}$ with obvious lip strain. On cephalometric analysis, she had ANB of $5^{\circ}$, normal growth pattern (SN-GoGn 33) and proclined and forwardly placed upper $\left(30^{\circ} / 7 \mathrm{~mm}\right)$ as well as lower incisors $\left(37^{\circ} / 7 \mathrm{~mm}\right)$.

Figure 1: Pretreatment facial and intra-oral photographs

\section{TREATMENT OBJECTIVES}

1. To obtain normal overjet and overbite to correct open bite

2. To achieve normally inclined and normally placed incisors

\section{TREATMENT PROCEDURE}

Extraction of all four first premolars and absolute anchorage with mini-implant screws were planned. Following steps were followed during the clinical procedure:

1. All first premolars were extracted and banding and bonding of brackets were done on March 31, 2012 (Figure 2).
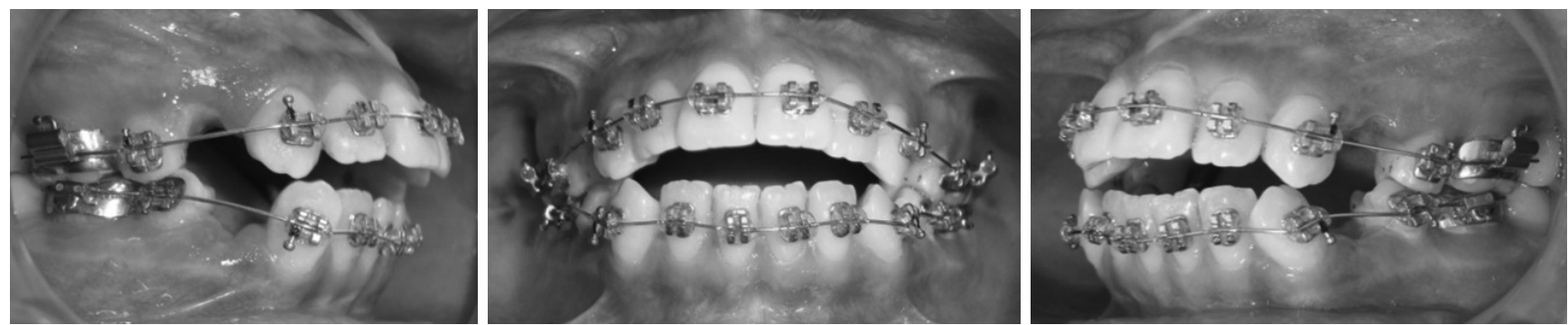

Figure 2: Treatment procedure with extraction of first premolars and bonding of brackets

2. Mini implant mini-screws were placed in infrazygomatic crest $(10 \mathrm{~mm})$ on May 30,2012 . The infrazygomatic miniscrews were preferred in place of interdental miniscrews considering the need for intrusion in the future.
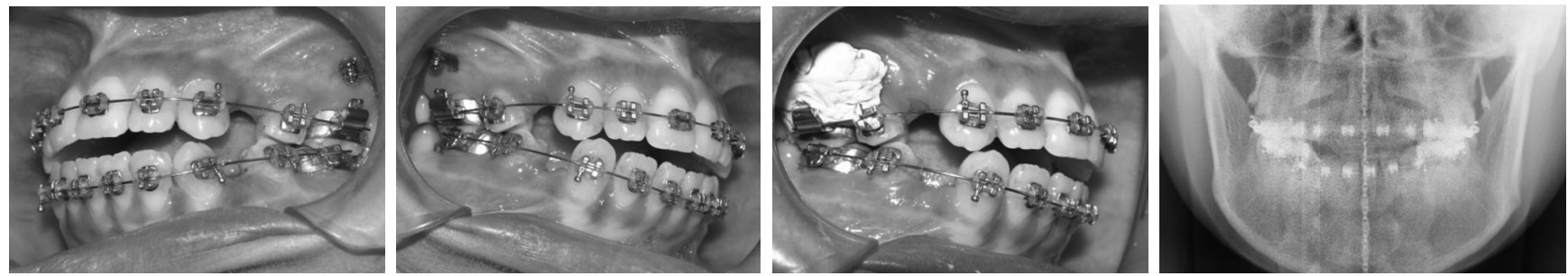

Figure 3: Placements of mini implants 
3. Bands were place in upper second molars, aligned, 0.019 " $\times 0.025$ " SS wire placed and upper posterior intrusion was started on December 4, 2012 (Figure 4).

4. Lower Mini implant screws were placed between first and second molars on both sides on January 13, 2013. Retraction started in both the arches (Figure 5).

5. On August 10, 2013, the normal overjet and overbite was obtained (Figure 6).
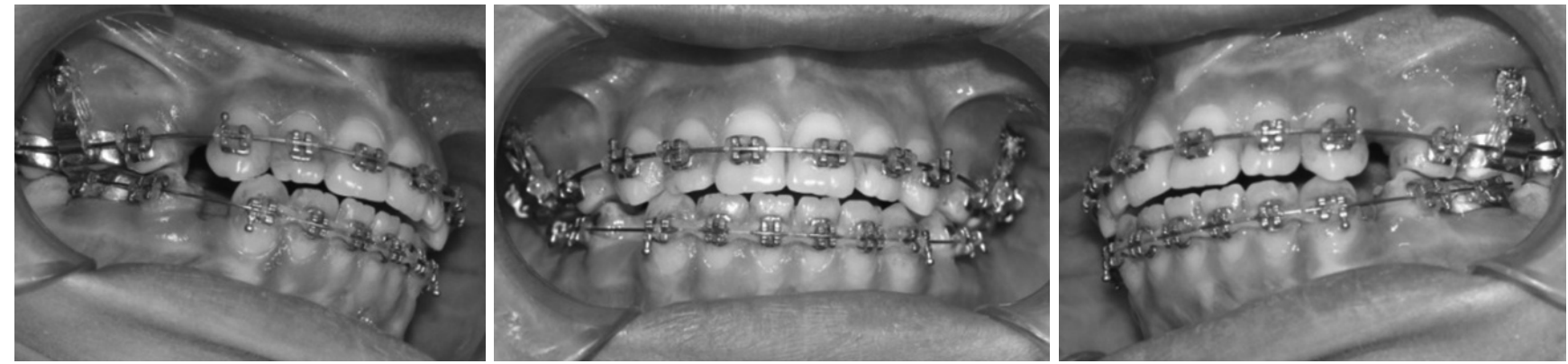

Figure 4: Banding of upper second pre-molars and intrusion of upper posterior segment

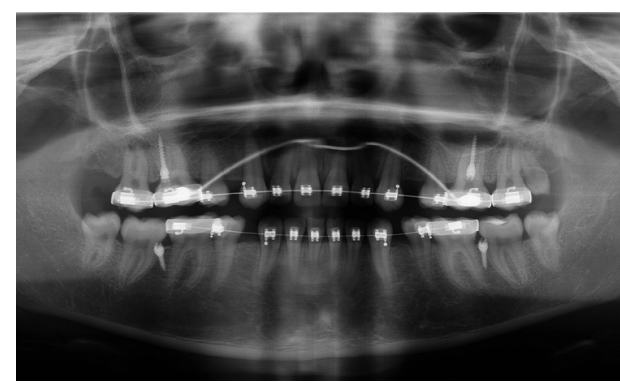

Figure 5: Placement of lower mini implants screws
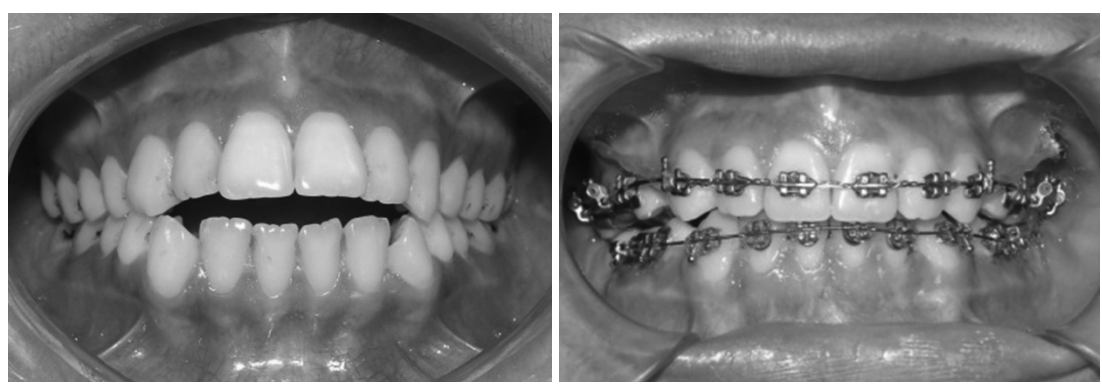

Figure 6: Comparison of pre-treatment and end of procedure photographs

Table 7: Distribution of subjects according to food habits

\begin{tabular}{|l|c|c|c|c|c|c|c|c|}
\hline & SNA & SNB & ANB & SN-GoGn & $\begin{array}{l}\text { Occlus- } \\
\text { sal Plane }\end{array}$ & $\begin{array}{c}\text { Upper } \\
\text { incisors }\end{array}$ & Lower incisors & $\begin{array}{l}\text { Inter-incis- } \\
\text { al angle }\end{array}$ \\
\hline Pre-treatment & 790 & 740 & 50 & 330 & 18.80 & $310 / 7 \mathrm{~mm}$ & $370 / 7 \mathrm{~mm}$ & 107 \\
\hline Progress & 790 & 740 & 50 & 330 & 17.80 & $200 / 2 \mathrm{~mm}$ & $20.50 / 4 \mathrm{~mm}$ & 135 \\
\hline
\end{tabular}

\section{DISCUSSION:}

Anterior open bite is considered to be one of the most difficult treatments. Proper diagnosis and treatment planning, successful treatment, and retention have been stressed for the long-term stability of open bite treatment. There are several factors that could be related to the development of open bite. Among these are an unfavorable mandibular growth pattern, heredity, imbalance between jaw postures, digitsucking habits, nasopharyngeal airway obstruction, tongue posture and activity and head position.
Various treatment modalities have been proposed for the correction of anterior open bites. Mizrahil ${ }^{15}$ described four modalities of treatment as growth modulation; orthodontic mechanotherapy; orthognathic surgery and combination of two or more of the above. It is important to determine which form of treatment is the most suitable for each individual case. Sarver and Weissman ${ }^{17}$ proposed some useful guidelines for the non-surgical treatment in adult patients with open bite who have no potential for growth modification. They discussed clinical results using extraction and retraction for dental open bite correction. It is emphasized that there are limited 
number of this type of treatment. Patients who are candidates for this type of therapy should meet the following criteria: proclined or procumbent maxillary or mandibular incisors, little or no gingival display upon smiling, normal craniofacial pattern, and no more than 2-3 mm of maxillary incisor exposure at rest. This case generally fulfilled these criteria. Accordingly, the treatment plan was developed and successful result was obtained. Although slight degree of intrusion was done, there was no change in the mandibular plane angle in this case.

Long-term stability of $A O B$ extraction treatment for permanent dentition has been documented18. After a mean period of 8 years, $74.2 \%$ of the sample had a "clinically stable" open bite correction.

\section{CONCLUSION:}

Drawbridge effect in the treatment of anterior dental open bite is an accepted treatment modality. When there is no skeletal discrepancy and the incisors are proclined and forwardly placed, the anterior open bite can be effectively corrected with this approach.

\section{REFERENCES}

1. Proffit WR, Fields HW. Contemporary Orthodontics, 3rd edn. St Lovis, MO: Mosby; 2000.

2. Tang EL. Occlusal features of Chinese adults in Hong Kong. Aust Orthod J. 1994; 13:159-63.

3. Proffit WR, Fields HW Jr, Moray LJ. Prevalence of malocclusion and orthodontic treatment need in the United States: Estimates from the NHANES III survey. Int J Adult Orthodon Orthognath Surg. 1998; 13:97-106.

4. Woon KC, Thong YL, Abdul Kadir R. Permanent dentition occlusion in Chinese, Indian and Malay groups in Malaysia. Aust Orthod J. 1989; 11:45-8.

5. Thilander B, Pena L, Infante C, Parada SS, de Mayorga C. Prevalence of malocclusion and orthodontic treatment need in children and adolescents in Bogota, Colombia. An epidemiological study related to different stages of dental development. Eur J Orthod. 2001; 23:153-67.

6. Alexander CD. Open bite, dental alveolar protusion, Class I malocclusion: a successful treatment result. Am J Orthod Dentofacial Orthop. 1999; 116:494-500.

7. Proffit WR, HW. F. Occlusal forces in normal- and long-face children. J Dent Res. 1983; 62:571-4.

8. Straub W. Malfunctions of the tongue. Am J Orthod. 1960; 62:404-24.

9. Sassouni V. A classification of skeletal facial types Am J Orthod Dentofacial Orthop. 1969; 55:109-23.

10. Kim HY, Han KU, Lim DD, Serraon MLP. Stability of anterior openbite correction with multiloop edgewise archwire therapy: A cephalometric follow-up study. Am J Orthod Dentorac Orthop. 2000; 118:43-54.

11. Beane RA. Nonsurgical management of anterior oopen bite: A review of the options. Seminars in Orthod. 1999; 5:275-83.

12. Kim YH. Anterior openbite and its treatment with multiloop edgewise archwire. Angle Orthod. 1987; 4:290-321.

13. Miyajima K, Lizuka T. Treatment Mechanics in Class III open bite malocclusion with Tip Edge technique. Am J Orthod Dentofac Orthop. 1996; 110:1-7.

14. Gavito GL, Wallen TR, Little RM, Joondeph DR. Anterior Open-bite malocclusion: A longitudinal 10-year postretention evaluation of orthodontically treated patients. Am J Orthod. 1985; 87:175-86.

15. Mizrahi E. A review of anterior open bite. Br J Orthod. 1978; 5:21-7.

16. Mclaughlin RP, Bennett JC, Trevissi HJ. Arch levelling and overbite control. In: Mclaughlin RP, Bennett JC, Trevissi HJ, editors. Systematized orthodontic treatment mechanics. Edinburgh: Mosby; 2001.

17. Sarver DM, Weissman. Nonsurgical treatment of open bite in non-growing patients. Am J Orthod Dentofac Orthop. 1995; 108:651-9.

18. de Freitas MR, Beltrão RT, Janson G, Henriques JF, Cançado RH. Long-term stability of anterior open bite extraction treatment in the permanent dentition. Am J Orthod Dentofacial Orthop 2004; 125:78-87. 